\title{
ENDOPLASMIC RETICULUM STRESS AND UNFOLDED PROTEIN RESPONSE PROFILE IN QUADRICEPS OF SARCOPENIC PATIENTS WITH RESPIRATORY DISEASES
}

\begin{tabular}{|c|c|}
\hline Journal: & Journal of Cellular Physiology \\
\hline Manuscript ID & JCP-18-0549.R1 \\
\hline Wiley - Manuscript type: & Original Research Article \\
\hline $\begin{array}{r}\text { Date Submitted by the } \\
\text { Author: }\end{array}$ & $n / a$ \\
\hline Complete List of Authors: & $\begin{array}{l}\text { Barreiro, Esther; IMIM-Hospital del Mar, UPF, PRBB, CIBERES, } \\
\text { Pulmonology-URMAR } \\
\text { Salazar-Degracia, Anna; IMIM, PRBB, URMAR } \\
\text { Sancho-Muñoz, Antonio; Hospital del Mar-IMIM, UPF, Pulmonology } \\
\text { Gea, Joaquim; IMIM-Hospital del Mar, Universitat Pompeu Fabra, } \\
\text { Barcelona Biomedical Research Park (PRBB), Respiratory Medicine }\end{array}$ \\
\hline Key Words: & $\begin{array}{l}\text { endoplasmic reticulum stress, unfolded protein response, chronic and } \\
\text { subacute respiratory sarcopenic conditions, COPD and lung cancer, lower } \\
\text { limb muscles }\end{array}$ \\
\hline
\end{tabular}


ENDOPLASMIC RETICULUM STRESS AND UNFOLDED PROTEIN RESPONSE PROFILE IN QUADRICEPS OF SARCOPENIC PATIENTS WITH RESPIRATORY

\section{DISEASES}

Esther Barreiro ${ }^{1,2}$, Anna Salazar-Degracia ${ }^{1}$, Antonio Sancho-Muñoz ${ }^{1}$, Joaquim Gea ${ }^{1,2}$

${ }^{1}$ Pulmonology Department-Muscle Wasting and Cachexia in Chronic Respiratory Diseases and Lung Cancer Research Group, IMIM-Hospital del Mar, Parc de Salut Mar, Health and Experimental Sciences Department (CEXS), Universitat Pompeu Fabra (UPF), Barcelona Biomedical Research Park (PRBB), Dr. Aiguader, 88, E-08003 Barcelona.

${ }^{2}$ Centro de Investigación en Red de Enfermedades Respiratorias (CIBERES), Instituto de Salud Carlos III (ISCIII), Monforte de Lemos, 5, E-28029 Madrid.

Corresponding author: Dr. Esther Barreiro, Pulmonology Department-URMAR, IMIMHospital del Mar, PRBB, Dr. Aiguader, 88, E-08003 Barcelona, Spain, Telephone: +34 93 316 0385, Fax: +34 93316 0410, e-mail: ebarreiro@imim.es

Word count: 4,800

Running head: ER stress and UPR in respiratory sarcopenia

KEY WORDS: endoplasmic reticulum stress; unfolded protein response; chronic and subacute respiratory sarcopenic conditions; COPD; lung cancer; lower limb muscles

\section{Number of text figures: 6}

\section{Number of tables: 2}

\section{Grant information:}

Contract grant sponsor: Instituto de Salud Carlos-III, contract grant numbers, CIBERES, FIS 14/00713 (FEDER), FIS 18/00075 (FEDER).

Contract grant sponsor: Spanish Respiratory Society (SEPAR), contract grant numbers, SEPAR 2016 and 2018.

Contract grant sponsor: Catalan Foundation of Pulmonology (FUCAP), contract grant 
numbers, FUCAP 2016.

Contract grant sponsor: Unrestricted research grant from Menarini SA 2018. 


\section{ABSTRACT}

Impaired muscle strength and mass (sarcopenia) are common in patients with respiratory cachexia, namely chronic obstructive pulmonary disease (COPD) and in lung cancer (LC)cachexia. Misfolded/unfolded proteins in endoplasmic reticulum (ER) induce the compensatory unfolded protein response (UPR). Expression of ER stress and UPR markers may be differentially upregulated in vastus lateralis (VL) of patients with respiratory sarcopenia associated with either a chronic condition (COPD) or subacute (LC)-cachexia. In VL specimens from 40 COPD patients $\left(n=21\right.$, sarcopenic, FFMI $16 \mathrm{~kg} / \mathrm{m}^{2}$ and $\mathrm{n}=19$, nonsarcopenic, FFMI $18 \mathrm{~kg} / \mathrm{m}^{2}$ ), 13 patients with LC-cachexia (FFMI $17 \mathrm{~kg} / \mathrm{m}^{2}$ ), and 19 healthy controls (FFMI, $19 \mathrm{~kg} / \mathrm{m}^{2}$ ), expression markers of ER stresss, UPR [protein kinase-like ER kinase (PERK), activating transcription factor (ATF)6, and inositol-requiring enzyme (IRE)1alpha], oxidative stress, autophagy, proteolysis, and apoptotis (qRT-PCR and immunoblotting), and fiber atrophy (histology) were assessed. Atrophy and muscle wasting and weakness were seen in both groups of sarcopenic patients. Compared to healthy controls, in muscles of LC-cachexia patients, expression of ER stress markers and UPR (three arms) was significantly upregulated, while in sarcopenic COPD, expression of a few ER stress markers and IRE1-alpha arm was upregulated. ER stress and an exaggerated UPR were observed in the VL muscle of patients with respiratory sarcopenia. The three branches of UPR were similarly upregulated in muscles of cancer cachectic patients, whereas in sarcopenic COPD patients, only IRE1 was upregulated. The differential profile of muscle UPR in chronic and subacute respiratory conditions offers a niche for the design of specific novel therapeutic approaches.

\section{Word count: 247}




\section{INTRODUCTION}

Muscle mass loss and dysfunction (sarcopenia) are characteristic features of patients with chronic respiratory and cardiac conditions and in cancer. Several studies have shown that for the same degree of airway obstruction in patients with chronic obstructive pulmonary disease (COPD), poor muscle mass and weakness of the quadriceps negatively influenced their quality of life and prognosis (Gosselink et al, 2000;Marquis et al, 2002;Seymour et al, 2010; Shrikrishna et al, 2012;Swallow et al, 2007;Gea et al, 2018a;Gea and Martinez-Llorens, 2018; Gea et al, 2018b). In patients with lung cancer (LC), muscle wasting and cachexia also reduced their quality of life and survival (Evans et al, 2008;Fearon et al, 2011). Despite that both respiratory and limb muscle dysfunction are present in patients with COPD, muscles of the lower limbs are usually more severely affected and have greater implications in their daily life activities (Barreiro et al, 2015;Barreiro, 2017;Barreiro et al, 2018;Barreiro and Jaitovich, 2018; Jaitovich and Barreiro, 2018; Maltais et al, 2014).

In the etiology of sarcopenia, several clinical aspects and molecular mechanisms are involved. Our group and others have contributed with several studies to the demonstration that systemic inflammation, increased oxidative stress, proteolytic signaling, autophagy and apoptosis, and epigenetic events participate in the multifactorial etiology of sarcopenia in COPD as well as in LC cachexia (Barreiro et al, 2015;Barreiro, 2017;Barreiro et al, 2018; Barreiro and Jaitovich, 2018;Jaitovich and Barreiro, 2018; Maltais et al, 2014). Indeed, similar biological and structural features were identified in the vastus lateralis (VL) of patients with respiratory cachexia (Puig-Vilanova et al, 2014c). The endoplasmic reticulum (ER) organelle is in charge of folding, processing, and trafficking of proteins within the cells. Accumulation of unfolded proteins may result from alterations in cellular homeostasis (aging, infections, hypoxia, glucose and calcium imbalance, etc.). When proper folding cannot be restored by chaperones and foldases, unfolded proteins are usually targeted to be degraded by 
ER through several pathways. Furthermore, unfolded protein response (UPR) is normally induced as a persistent accumulation of unfolded proteins within eukaryote cells (Chakrabarti et al, 2011;Kelsen, 2016). Three ER transmembrane receptors with distinct functions have been shown to mediate UPR as part of a complex signaling program (Chakrabarti et al, 2011;Kelsen, 2016). Importantly, ER-induced UPR was also shown to signal muscle development and regeneration (Bohnert et al, 2017; Nakanishi et al, 2005;Xiong et al, 2017). Markers of UPR were also highly activated in skeletal muscles of mice with LC-induced cachexia and blockade of UPR with 4-phenylbutyrate induced a less fatigue-resistant phenotype in the muscles of the same animals (Bohnert et al, 2016). These findings suggest that UPR plays a key role in muscle mass maintenance, at least in experimental models of cachexia. Nonetheless, investigations are needed to elucidate the potential role of UPR in muscles of patients with sarcopenia associated with respiratory diseases.

Therefore, we hypothesized whether the expression of ER stress and UPR markers may be upregulated to different extent in the VL of patients with sarcopenia associated with respiratory diseases of either a chronic condition (COPD) or a subacute disease (LC). Accordingly, the study objectives were to explore in VL specimens obtained from COPD patients with and without sarcopenia, in those with LC-induced cachexia, and in age-matched healthy control subjects: 1) well-known markers of ER stress, 2) markers of UPR pathways [activating transcription factor (ATF)6, protein kinase-like ER kinase (PERK), and inositolrequiring enzyme (IRE)1], 3) markers of oxidative stress, autophagy, apoptosis, and proteolysis, and 4) muscle phenotype (fiber types and morphometry). Gene expression profile was analyzed for all the target markers along with protein levels of the markers whose expression significantly differed in the muscles of any study group of patients from those detected in the control subjects. 


\section{MATERIALS AND METHODS}

(See detailed methodologies in the online supporting information)

\section{Study design and population}

This was a prospective, controlled, cross-sectional study, in which 40 male patients with stable COPD (Miravitlles and Soler-Cataluna, 2017;Miravitlles et al, 2017;Vogelmeier et al, 2017) and 13 male patients with lung cancer cachexia according to the international consensus criteria (Evans et al, 2008; Fearon et al, 2011) were recruited. Additionally, 19 agematched male healthy controls were recruited from the general population (patients' relatives or friends) at Hospital del Mar (Barcelona). COPD patients were further subdivided into those with and without loss of muscle mass and muscle strength (sarcopenic COPD, n=21 and nonsarcopenic COPD, $\mathrm{n}=19$ ) following the international consensus criteria on muscle wasting and sarcopenia (Cao and Morley, 2016; Muscaritoli et al, 2010) and published criteria (PuigVilanova et al, 2014c). Lung cancer patients had not previously received any specific treatment for the lung neoplasm: chemotherapy, radiotherapy or systemic corticosteroids at the time of entry into this specific investigation. Clinical staging was assessed in all cachectic patients with lung cancer following currently available international guidelines (Chansky et al, 2017). All study groups of individuals were Caucasian. In the present investigation, 9 sarcopenic COPD patients and 2 age-matched sedentary control subjects were also involved in another study aimed to investigate the proteolytic mechanisms involved in sarcopenic muscles of patients with severe COPD and in those with LC-cachexia (Puig-Vilanova et al, 2014c).

The current investigation was designed in accordance with both the ethical standards on human experimentation in our institution and the World Medical Association guidelines (Helsinki Declaration of 2008) for research on human beings. Approval was obtained from the institutional Ethics Committee on Human Investigation (Hospital del Mar-IMIM, 
Barcelona). Informed written consent was obtained from all individuals.

\section{Anthropometrical and functional assessment}

Anthropometrical, nutritional, and lung function evaluations were conducted as previously reported (Coin et al, 2008; Steiner et al, 2002). Quadriceps muscle strength was evaluated as formerly described (Coronell et al, 2004; Swallow et al, 2007).

\section{Muscle biopsies}

Muscle samples were obtained from the quadriceps muscle (vastus lateralis, VL) of all groups of patients and control subjects using the open muscle biopsy technique, as previously described (Fermoselle et al, 2012;Puig-Vilanova et al, 2014c;Puig-Vilanova et al, 2014a;PuigVilanova et al, 2015;Puig-Vilanova et al, 2014b).

\section{Biological analyses}

Muscle fiber counts and morphometry. On three micrometer muscle paraffin-embedded sections from all groups of patients and controls, MyHC-I (slow-twitch fibers) and -II (fasttwitch fibers) isoforms were identified using anti-MyHC-I antibody (Sigma-Aldrich, Saint Louis, MO, USA), following methodologies previously published (Fermoselle et al, 2012;Puig-Vilanova et al, 2014c;Puig-Vilanova et al, 2014a;Puig-Vilanova et al, 2015). $R N A$ isolation. Total RNA was first isolated from snap-frozen skeletal muscle specimens as previously described (Puig-Vilanova et al, 2015).

Gene expression was assessed using $q R T-P C R$. MicroRNA RT was performed using TaqMan ${ }^{\circledR}$ microRNA assays (Life Technologies) following the manufacturer's instructions and previous studies (Table E1) (Livak and Schmittgen, 2001;Puig-Vilanova et al, 2015).

Immunoblotting. Protein levels of the different molecular markers analyzed in the study were explored by means of immunoblotting procedures as previously described (Barreiro et al, 2018; Chacon-Cabrera et al, 2016;Puig-Vilanova et al, 2014c;Salazar-Degracia et al, 2016; Salazar-Degracia et al, 2018). The following primary antibodies were used: anti-binding 
immunoglobulin protein (BIP; 1:1000, ab37073) antibody (Abcam, Cambridge, UK), antiprotein disulphide-isomerase-3 (PDIA3; 1:1000, ADI-SPA-725-F) antibody (Enzo life science Framingdale, NY, USA), anti-phosphatidylinositol 3-kinase (PI3K; 1:1000, 3358S) antibody (Cell signaling, Boston, MA, USA), anti- activating transcription factor 6 (ATF6; 1:100, ab37149), anti-protein kinase R (PKR)-like endoplasmic reticulum kinase (PERK; 1:1000, ab79483), anti-phospho-PERK (1:1000, ab192591), anti-eukaryotic translation initiation factor 2alpha (eiF2a; 1:500, ab181467), anti-phospho-eiF2a (1:1000, ab32157), antiC/EBP-homologous protein (CHOP; 1:2000, ab11419), anti-inositol-requiring enzyme 1 (IRE1; 1:1000, ab37073), anti-tumor necrosis factor receptor associated factor 2 (TRAF2; 1:1000, ab37118), anti-X-box binding protein 1 (XBP1; 1:1000, ab37152) antibodies from Abcam, anti-microtubule-associated protein 1 light chain 3 (LC3; 1:1000, \#2775S) antibody (Cell signaling), anti-nucleoporin p62 (p62; 1:1000, P0067) antibody (Sigma-Aldrich St. Louis, MO, USA), anti-signal-regulating kinase 1 (ASK1; 1:500, sc-5294) antibody from Santa Cruz (Santa Cruz, CA, USA), anti-malondialdehyde-protein adducts (MDA; 1:4000, MD20A-G1b) antibody (Academy Bio-Medical Company, Houston, TX, USA), and antiglyceraldehyde 3-phosphate dehydrogenase (GAPDH; 1:2000, sc-25778) antibody (Santa Cruz).To validate equal protein loading across lanes, the glycolytic enzyme GAPDH was used as the protein loading control in all immunoblots (Figures E2-E5). Standard stripping methodologies were employed to detect the phosphorylated proteins (PERK and EiF2a) and the loading control GAPDH for each of the markers (BIP, PDIA3, PI3K, ATF6, PERK, EiF2a, CHOP, IRE1, TRAF2, XBP1, LC3B, p62, ASK1 and MDA).

\section{Statistical analyses}

Statistical power was calculated using specific software (StudySize 2.0, CreoStat HB, Frolunda, Sweden). FFMI was selected as the target variable on the basis of the T-test to estimate the statistical power between healthy controls and LC-cachexia patients. On the 
basis of a standard power statistics established at a minimum of $80 \%$ and assuming an alpha error of 0.05 , the statistical power was sufficiently high to detect a minimum difference of two points between groups in the sample size $(\mathrm{N}=11$ minimum number of subjects in each group) and standard deviation. Normality of the study variables was checked using ShapiroWilk test. The comparisons between study groups were analyzed using one-way analysis of variance (ANOVA), in which Tukey's post-hoc analyses was used to adjust for multiple comparisons. Comparisons were explored between healthy controls and either any group of COPD patients or LC-cachexia patients. Pearson's Chi-Square test was employed to assess potential differences between groups in the qualitative variables such as smoking history. Correlations between clinical and biological variables were explored using the Pearson's correlation coefficient. Variables that described the clinical characteristics of the study population are represented as mean and standard deviation, whereas all the molecular variables are represented as mean and $95 \%$ confidence interval. A level of significance of $P \leq 0.05$ was established. Statistical analyses were performed using the Statistical Package for the Social Sciences (Portable SPSS, PASW statistics 18.0 version for windows, SPSS Inc., Chicago, IL, USA).

\section{RESULTS}

\section{Clinical characteristics}

Clinical and functional variables of control subjects, COPD patients and LC-cachexia patients are illustrated in Table 1. Age did not significantly differ among the study subjects. Body composition as measured by body mass index (BMI) and fat-free mass index (FFMI) was significantly reduced in both COPD and LC-cachexia patients (Table 1). Additionally, body weight, BMI and FFMI were also significantly lower in sarcopenic COPD patients than in either healthy controls or non-sarcopenic patients, while no differences were observed 
between the latter patients and the healthy controls (Table 1). Body weight change, expressed as $\mathrm{kg}$ lost in the previous year, was also significantly lower in both LC-cachexia and COPD patients, especially in sarcopenic COPD patients, than control subjects (Table 1). In all groups of patients, the proportions of active smokers were similar and were significantly greater that those observed in the healthy controls (Table 1). The number of packs-year, however, was similar among all study groups (Table 1). No significant correlations were detected between smoking history and any of the study biological variables among any study group. All COPD patients exhibited severe airflow limitation and moderate functional signs of emphysema (diffusion capacity status), whereas LC-cachexia patients showed a mild-to-moderate airflow obstruction and no functional signs of emphysema. COPD patients exhibited very mild hypoxemia with no hypercapnia compared to controls (Table 1). Compared to healthy controls, in LC-cachexia and COPD patients, exercise capacity and quadriceps strength were significantly reduced (Table 1). Levels of C-reactive protein, fibrinogen, and globular sedimentation velocity were also significantly greater in COPD and LC-cachexia patients, especially in the latter patients, than the controls (Table 1).

\section{Muscle structural features}

As expected, the proportions of slow-twitch fibers were significantly lower in the VL of both groups of patients than in healthy subjects (Table 2 and Figure E1). In VL, the crosssectional area of fast-twitch fibers was significantly smaller in LC-cachexia and COPD patients, particularly in sarcopenic patients, than in control subjects, while that of slow-twitch fibers was only reduced in COPD patients (Table 2 and Figure E1).

\section{Markers of ER stress and UPR in sarcopenic muscles}

ER stress. Compared to healthy controls, gene expression levels of heat shock protein (HSP)60, calnexin, and PI3K were significantly upregulated in the VL of COPD patients as a whole and LC-cachexia patients (Figure 1A). Furthermore, in VL of LC-cachexia patients, 
gene expression levels of binding immunoglobulin protein (BIP), HSP70, calreticulin, and protein disulfide-isomerase A (PDIA)3 were also upregulated compared to the controls (Figure 1A). Among LC-cachexia patients, significant correlations were found between gene expression levels of the ER stress markers HSP60 and calnexin and weight loss $(r=0.844$ and $\mathrm{p}=0.035$ and $\mathrm{r}=0.813$ and $\mathrm{p}=0.049$, respectively). In the same group of patients, correlations were detected between gene expression of the ER stress marker PDIA3 and the clinical variables FFMI and weigh loss $[\mathrm{r}=0.669$ and $\mathrm{p}=0.101$ (almost significant) and $\mathrm{r}=0.754$ and $\mathrm{p}=0.03$, respectively). Muscle gene expression levels of PDIA3 also significantly correlated with the proportions of type I (positively) and type II (negatively) fibers ( $r=0.740, r=-0740$ and $\mathrm{p}=0.036$, respectively) among LC-cachexia patients. In VL of the same patients, gene expression levels of BAX and BCL-2 also significantly correlated with the proportions of type I and type II fibers ( $\mathrm{r}=0.731$ and $\mathrm{p}=0.014$ and $\mathrm{r}=0.598$ and $\mathrm{p}=0.042$, respectively).

Interestingly, protein levels of PDIA3 and PI3K were significantly greater in the VL of both COPD as a group and LC-cachexia patients than in the control subjects (Figures 1C-1D, and E2). Protein levels of BIP were almost significantly increased $(p=0.084)$ in the VL of the LCcachexia patients compared to the control subjects, while no significant differences were observed among the COPD patients (Figures 1B and E2).

ATF6 arm. Gene expression and protein levels of activating transcription factor (ATF)6 pathway were significantly upregulated in VL of LC-cachexia, and ATF6 protein content was also increased in muscles of sarcopenic COPD patients (Figures 2A-2B and E3A).

PERK arm. C/EBP-homologous protein (CHOP) gene expression was significantly greater in muscles of LC-cachexia and in both groups of COPD patients, while that of PERK and ATF4 did not differ among the study groups (Figure 3A). Protein levels of activated (phosphorylated) PERK, EiF2a, and CHOP were significantly higher in the VL of the LCcachexia patients than in the controls (Figures 3B-3D and E3B). Moreover, protein levels of 
CHOP were also significantly increased in the VL of COPD patients as a whole and in the sarcopenic group (Figures 3D and E3B).

IRE1 arm. Gene expression of tumor necrosis factor receptor associated factor (TRAF)2 and $\mathrm{X}$-box binding protein (XBP)1, as markers of IRE1 pathway, was upregulated in VL of COPD patients and the latter marker also in LC-cachexia group (Figure 4A). Moreover, TRAF2 gene expression was upregulated in muscles of both sarcopenic and non-sarcopenic COPD patients (Figure 4A). Protein levels of IRE1 did not significantly differ among the study groups (Figures 4B and E4). TRAF2 protein levels were significantly increased in the VL of both groups of COPD patients (Figures 4C and E4). Interestingly, protein levels of unspliced XBP1u and spliced XBP1s were significant greater in the VL of both LC-cachexia and COPD patients as a whole and in sarcopenic (XBP1u) than in the controls (Figures 4D4E and $\mathrm{E} 4)$.

\section{Markers of oxidative stress, autophagy, proteolysis, and apoptosis in muscles}

Gene expression of atrogin-1 and MuRF-1 was only significantly upregulated in VL of LCcachexia compared to healthy controls (Figure 5A). Protein levels of microtubule-associated proteins 1A/1B light chain 3B (LC3)B were only significantly greater in the VL of all COPD patients as a whole and in the sarcopenic patients than in control subjects (Figures 5B and E5), while protein levels of the autophagy marker p62 did not significantly differ among the study groups (Figures 5C and E5). Protein oxidation levels as measured by MDA-protein adduct levels were significantly higher in the VL of all study groups of patients than in healthy controls (Figures 5D and E5).

Gene expression of apoptosis markers such as caspase-7, caspase-9, and apoptosis signalregulating kinase (ASK) were significantly upregulated in VL of LC-cachexia patients compared to the controls (Figure 6A). Moreover, ASK gene expression was also upregulated in muscles of both sarcopenic and non-sarcopenic COPD patients and as a whole compared to 
healthy controls (Figure 6A). Protein levels of ASK were also significantly increased in the VL of LC-cachexia and COPD patients as a whole, especially in the sarcopenic COPD patients (an almost significant increase) (Figures 6B and E5). Significant correlations were found between caspase-7 gene expression and the proportions of type I and type II fibers ( $\mathrm{r}=0.874$ and $\mathrm{r}=-0.874, \mathrm{p}=0.005$, respectively) in the muscles of the LC-cachexia patients.

\section{DISCUSSION}

The current investigation has addressed a novel relevant question in well-characterized patients with respiratory sarcopenia of two different etiologies, chronic (COPD) versus subacute (LC) conditions. Sarcopenic COPD patients had a more severe airway obstruction but diffusion capacity was similar to that seen in patients with normal body composition. Despite that $\mathrm{PaO}_{2}$ levels were significantly lower in all groups of COPD patients compared to healthy controls, such a reduction was very mild even in the sarcopenic patients. As expected, in the VL of both LC-cachexia patients and sarcopenic COPD patients, muscle phenotype was characterized by a rise in the proportions of fast-twitch fibers, while its size was significantly smaller as an indication of muscle atrophy. These findings are similar to those previously reported in limb muscles from cachectic COPD patients and in those with LC (Barreiro et al, 2018; Fermoselle et al, 2012;Puig-Vilanova et al, 2014c). Moreover, in the sarcopenic COPD patients, slow-twitch cross-sectional area was also reduced compared to that seen in the controls. The expression profile of markers of ER stress and UPR differs to some extent in sarcopenic muscles of patients with COPD from those with LC cachexia. These are novel findings that prompt UPR as a potential signaling driver of muscle atrophy in patients with respiratory diseases.

Correct folding, processing, and trafficking of proteins take place in the ER, which also plays a central role in protein synthesis and cell calcium homeostasis (Almanza et al, 
2018). ER stress results from the accumulation of misfolded proteins in response to injurious conditions that disrupt cell homeostasis. Intrinsic ER perturbations such as those occurring in cancer (genetic instability and mutations) and in neurodegenerative disease may result in ER stress (Almanza et al, 2018). Moreover, extrinsic perturbations derived from microenvironmental stress (depletion of nutrients and oxygen and acidosis) and increased reactive oxygen species production also lead to ER stress (Almanza et al, 2018).

Despite that UPR has been recently shown to underlie the pathophysiology of several acute (critical illness) and chronic lung conditions (cystic fibrosis, pulmonary fibrosis, and COPD) (Baek et al, 2012;Bartoszewski et al, 2008;Hassan et al, 2014;Lawson et al, 2011), its role in skeletal muscles is not well known, let alone in specific conditions characterized by severe muscle mass loss. Activation of ER stress and UPR may also take place in skeletal muscles during exercise and aging (Bohnert et al, 2017). As protein folding in the ER is calcium-, redox-, and energy-dependent, ER stress may be a relevant mechanism leading to muscle wasting in chronic diseases. In fact, perturbations in those homeostatic processes have been reported in the lower limb muscles of COPD patients with muscle dysfunction and wasting (Barreiro et al, 2010;Fermoselle et al, 2012;Puig-Vilanova et al, 2014c;Puig-Vilanova et al, 2014b;Puig-Vilanova et al, 2015). In the current study, we sought to explore whether ER stress and UPR may be upregulated in sarcopenic muscles with two different respiratory diseases: chronic versus subacute disease.

ER stress activates the UPR that is mediated by three ER transmembrane sensors identified as ATF6, PERK, and IRE1. UPR reverses ER stress by slowing the flow of new proteins into ER through a series of transcriptional, translational, and post-translational processes that increase ER capacity for protein folding and processing, enhance elimination of misfolded proteins, and expand the size of ER(Kelsen, 2016). Importantly, UPR may also induce apoptosis and protein degradation if ER stress cannot be reversed (Chakrabarti et al, 
2011;Kelsen, 2016). Indeed, restoration of cell homeostasis and survival or apoptosis is also determined upon activation of the UPR signaling pathways (Chakrabarti et al, 2011;Kelsen, 2016).

Posttranslational processing of all membrane and secretory proteins in the ER comprises a variety of resident chaperones, foldases, oxido-reductases, and disulfide isomerases(Schroder and Kaufman, 2005). These chaperones promote disulfide bonds and glycosylation of proteins in the ER under a process of quality control before proteins exit this organelle. Molecular chaperones such as calnexin, calreticulin, BIP, and other heat shock proteins (HSP) specifically bind unfolded or misfolded proteins in the ER in order to correct folding. In the present study, expression levels of the chaperones HSP60, calnexin, and PI3K were upregulated in the VL of both sarcopenic COPD and LC-induced cachexia patients. Additionally, in the lower limb muscles of the latter patients, expression levels of BIP, HSP70, calnexin, calreticulin, and PDIA3 were also significantly upregulated. These findings imply that ER stress is present in the peripheral muscles of patients with respiratory sarcopenia, and particularly in those with LC. In keeping with, an upregulation of ER stress markers was also seen in the hindlimb muscles of cachectic mice bearing the Lewis lung carcinoma (Bohnert et al, 2016). However, as far as we are concerned the current investigation is the first to report the presence of ER stress fingerprints in the skeletal muscles of actual patients with respiratory sarcopenia of two different etiologies and time-frame: chronic versus subacute conditions.

In response to unfolded or misfolded proteins, ATF6 pathway is activated through a series of translocation and irreversible proteolytic processing steps leading to the upregulation of pro-survival transcriptional programs (Chakrabarti et al, 2011). Gene expression levels of ATF6 were only significantly upregulated in the VL of patients with LC-induced cachexia, while protein levels of this marker were also significantly increased in the limb muscles of the 
sarcopenic COPD patients. Interestingly, ATF6 may also interact with protein degradation pathways such as the ubiquitin-proteasome system to enhance proteolysis and autophagy. Atrogin-1 and MuRF-1 gene expression levels were significantly upregulated in the VL of patients with cancer cachexia. Nonetheless, protein levels of the autophagy marker LC3B were only significantly greater in the muscles of the sarcopenic COPD patients, thus suggesting that ATF6 rather triggers the ubiquitin-proteasome pathway in muscles of cancer cachectic patients than autophagy. Previous studies also demonstrated a rise in autophagy markers in the VL of cachectic COPD but not in those with LC (Guo et al, 2013;PuigVilanova et al, 2014c).

Both pro-survival and pro-apoptotic programs are signaled by the PERK arm of UPR following the accumulation of unfolded or misfolded proteins. The transmembrane protein PERK consists of a cytosolic protein kinase domain and an ER luminal stress sensor. In the study, protein levels of active PERK which phosphorylates eIF2a, were significantly greater in the VL of the LC-cachexia patients. During ER stress phosphorylation of eIF2alpha by PERK downregulates protein synthesis by blocking translation (Almanza et al, 2018; Rowlands et al, 1988). Consistently, protein levels of p-EIF2alpha were also significantly higher in the muscles of cancer cachectic patients, thus implying that PERK arm was indeed activated in the lower limb muscles of these patients.

Gene expression of C/EBP homologous protein (CHOP) was upregulated in the quadriceps of patients with LC cachexia and in those with COPD to a lower extent. Moreover, protein levels of CHOP were also significantly increased in the lower limb muscles of both LC-cachexia and sarcopenic COPD patients. ATF6 can also induce the expression of XBP1 and CHOP to enhance UPR signaling (Almanza et al, 2018). In line with this, gene expression and protein levels of CHOP and XBP1 were also significantly greater in the VL of LCcachexia and in COPD patients, especially in sarcopenic (CHOP and XBP1u proteins), thus 
implying that these three pathways may enhance UPR signaling cascades and downstream mechanisms in muscles of those patients. Importantly, increased expression of CHOP may result in oxidative stress, ATP depletion, and cell death (Almanza et al, 2018; Chakrabarti et al, 2011;Hiramatsu et al, 2014). In the present study, oxidative stress levels were significantly greater in the VL of both cancer cachectic and all groups of COPD patients, as also consistently demonstrated in previous studies (Barreiro et al, 2010; Barreiro et al, 2018; PuigVilanova et al, 2014c). Expression levels of markers of apoptosis such as caspase 7 and 9 and ASK were also upregulated in the VL of patients with cancer cachexia. Despite that no correlations were found between oxidative stress and autophagy or apoptosis markers, these observations suggest that apoptosis may preferentially mediate muscle mass loss in patients with LC-induced cachexia and UPR can be a powerful signaling mechanism. Indeed, previous investigations have also shown that apoptosis rather than proteolysis was the major mechanism leading to muscle wasting in animal models of cancer cachexia (Salazar-Degracia et al, 2016) and to a lower degree in COPD sarcopenia (Agusti et al, 2002).

IRE1 signals both pro-survival and pro-apoptotic programs in response to misfolded and unfolded proteins (Chakrabarti et al, 2011). IRE1 has endoribonuclease and serinethreonine kinase domains that exert different actions. Cytosolic IRE1 dimers also interact

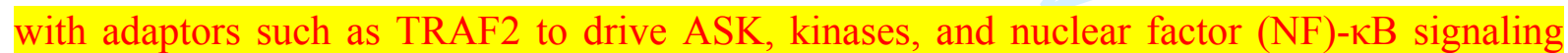
pathways (Hu et al, 2006; Nguyen et al, 2004). Importantly, gene and protein expression levels of TRAF2 were significantly upregulated in the lower limb muscles of both groups of COPD patients. Gene and protein expression levels of ASK were also increased in the VL of cancer cachectic and in COPD patients. Collectively, these findings suggest that TRAF2 UPR marker may signal the initiation of apoptosis leading to muscle atrophy in both conditions of respiratory sarcopenia. In line with this, IRE branch of UPR was also upregulated in the hindlimb muscles of LC cachectic mice (Bohnert et al, 2016). Protein synthesis and the load 
of new proteins entering the ER are reduced by the action of IRE1 pathway such as XBP1. Interestingly, in the VL of patients with LC-cachexia and in COPD, gene expression levels of XBP1 were upregulated compared to levels in the controls. Furthermore, protein levels of the spliced and unspliced isoforms, XBP1s and XBP1u respectively, were also significantly increased in the muscles of both cancer cachectic and sarcopenic COPD patients.

\section{Study critique}

In the current investigation, upregulation of the expression of the three branches of UPR and ER stress markers in the lower limb muscles of patients with respiratory sarcopenia was a relevant observation. Of note are the significantly greater levels of expression and number of UPR markers that were upregulated in the quadriceps of the cancer cachectic patients with respect to levels encountered in the muscles of the COPD patients, even those with sarcopenia. Indeed, significant correlations between nutritional status (FFMI), body weight loss, and muscle fiber types with biological variables were only seen among patients with LC cachexia. It is very likely that the faster rate of muscle mass loss observed in cancer cachexia as opposed to chronic disease (COPD) may account for the significantly stronger UPR and ER stress responses observed in the muscles of patients with LC cachexia. Indeed, as the main purpose of UPR is to restore ER function in order to improve proper folding under stress conditions, a more exaggerated response in muscles of LC-cachexia patients may help prevent additional loss. Nonetheless, the current cross-sectional study design did not allow us to ascertain whether ER stress and UPR may be a trigger of muscle loss or may protect muscles from undergoing further protein loss. Intervention studies may help elucidate this relevant question in the near-future. Despite these concerns, the current investigation is the first to demonstrate the presence of ER stress and UPR activation in the lower limb muscles of patients with two major respiratory conditions. 
It should also be mentioned that differences in gene expression and protein levels between patients and control subjects were not exactly consistent for all the study markers. Methodological issues directly related to either RT-PCR or immunoblotting analyses may account for those differences. For some of the markers, the magnitude of the differences between LC-cachexia patients and healthy controls were higher than those detected between COPD patients and the controls, especially for gene expression. Finally, it should be mentioned that despite the interest in assessing potential differences in expression levels of the study markers between non-sarcopenic and sarcopenic COPD patients, the investigation was not specifically targeted to explore such a question. Importantly, the degree of lung function, exercise capacity, and muscle strength impairment was similar in both groups of COPD patients in contrast to previous investigations, in which cachectic COPD patients were more severely affected than non-sarcopenic patients (Barreiro et al, 2008; Barreiro et al, 2009; Fermoselle et al, 2012;Puig-Vilanova et al, 2014c). This may partly account for discrepancies in expression levels of some of the study markers.

\section{Conclusions}

ER stress and an exaggerated UPR were observed in the VL muscle of patients with respiratory sarcopenia and cachexia, particularly in those with LC. The three branches of UPR were similarly upregulated in muscles of cancer cachectic patients, whereas in the sarcopenic COPD patients, IRE1 arm was mostly upregulated in their VL. The differential expression profile of ER stress and UPR markers observed in chronic and acute respiratory diseases offers a niche for the design of novel customized therapeutic approaches which may encompass exercise training along with pharmacological strategies purported to boost ER function. Eventually, these strategies will have implications in the clinical management of the patients. 


\section{LIST OF ABBREVIATIONS}

ANOVA: one-way analysis of variance

ASK: apoptosis signal-regulating kinase

ATF: activating transcription factor

BMI: body mass index

BIP: binding immunoglobulin protein

BSA: bovine serum albumin

CHOP: C/EBP-homologous protein

COPD: chronic obstructive pulmonary disease

ER: endoplasmic reticulum

LC: lung cancer

LC3: microtubule-associated protein 1 light chain 3

EiF2 $\alpha$ : eukaryotic translation initiation factor 2 alpha

GAPDH: glyceraldehyde 3-phosphate dehydrogenase

HSP: heat shock protein

IRE: inositol-requiring enzyme

MDA: malondialdehyde

MyHC: myosin heavy chain

NF: nuclear factor

P62: nucleoporin p62

PDIA: protein disulfide-isomerase

PERK: protein kinase-like ER kinase

QMVC: quadriceps maximal velocity contraction

SDS: sodium dodecyl sulfate

TRAF2: tumor necrosis factor receptor associated factor 
UPR: unfolded protein response

VL: vastus lateralis

XBP1: X-box binding protein 


\section{ACKNOWLEDGEMENTS}

The authors gratefully acknowledge the help provided by Dr. Ester Puig-Vilanova with part of the molecular experiments.

Authors' conflicts of interest in relation to the study: None to declare.

Editorial support: None to declare.

Authors' contributions: Study conception and design: EB; Patient assessment and recruitment and sample collection: ASM; Molecular biology analyses: ASD; Statistical analyses and data interpretation: $\mathrm{EB}, \mathrm{ASD}, \mathrm{JG}$; manuscript drafting and intellectual input: $\mathrm{EB}$, ASD, ASM, JG; manuscript writing final version: EB. 


\section{Literature Cited}

Agusti AG, Sauleda J, Miralles C, Gomez C, Togores B, Sala E, Batle S, Busquets X (2002). Skeletal muscle apoptosis and weight loss in chronic obstructive pulmonary disease. Am J Respir Crit Care Med 166:485-489.

Almanza A, Carlesso A, Chintha C, Creedican S, Doultsinos D, Leuzzi B, Luis A, McCarthy N, Montibeller L, More S, Papaioannou A, Puschel F, Sassano ML, Skoko J, Agostinis P, de BJ, Eriksson LA, Fulda S, Gorman AM, Healy S, Kozlov A, Munoz-Pinedo C, Rehm M, Chevet E, Samali A (2018). Endoplasmic reticulum stress signalling - from basic mechanisms to clinical applications. FEBS J.

Baek HA, Kim DS, Park HS, Jang KY, Kang MJ, Lee DG, Moon WS, Chae HJ, Chung MJ (2012). Involvement of endoplasmic reticulum stress in myofibroblastic differentiation of lung fibroblasts. Am J Respir Cell Mol Biol 46:731-739.

Barreiro E (2017). Skeletal Muscle Dysfunction in COPD: Novelties in The Last Decade. Arch Bronconeumol 53:43-44.

Barreiro E, Bustamante V, Cejudo P, Galdiz JB, Gea J, de LP, Martinez-Llorens J, Ortega F, Puente-Maestu L, Roca J, Rodriguez-Gonzalez Moro JM (2015). Guidelines for the evaluation and treatment of muscle dysfunction in patients with chronic obstructive pulmonary disease. Arch Bronconeumol 51:384-395.

Barreiro E, Jaitovich A (2018). Muscle atrophy in chronic obstructive pulmonary disease: molecular basis and potential therapeutic targets. J Thorac Dis 10:S1415-S1424.

Barreiro E, Peinado VI, Galdiz JB, Ferrer E, Marin-Corral J, Sanchez F, Gea J, Barbera JA (2010). Cigarette smoke-induced oxidative stress: A role in chronic obstructive pulmonary disease skeletal muscle dysfunction. Am J Respir Crit Care Med 182:477-488.

Barreiro E, Puig-Vilanova E, Salazar-Degracia A, Pascual-Guardia S, Casadevall C, Gea J (2018). The phosphodiesterase-4 inhibitor roflumilast reverts proteolysis in skeletal muscle cells of patients with COPD cachexia. J Appl Physiol (1985 ) 125:287-303.

Barreiro E, Rabinovich R, Marin-Corral J, Barbera JA, Gea J, Roca J (2009). Chronic endurance exercise induces quadriceps nitrosative stress in patients with severe COPD. Thorax 64:13-19.

Barreiro E, Schols AM, Polkey MI, Galdiz JB, Gosker HR, Swallow EB, Coronell C, Gea J (2008). Cytokine profile in quadriceps muscles of patients with severe COPD. Thorax 63:100107.

Bartoszewski R, Rab A, Jurkuvenaite A, Mazur M, Wakefield J, Collawn JF, Bebok Z (2008). Activation of the unfolded protein response by deltaF508 CFTR. Am J Respir Cell Mol Biol 39:448-457.

Bohnert KR, Gallot YS, Sato S, Xiong G, Hindi SM, Kumar A (2016). Inhibition of ER stress and unfolding protein response pathways causes skeletal muscle wasting during cancer cachexia. FASEB J 30:3053-3068.

Bohnert KR, McMillan JD, Kumar A (2017). Emerging roles of ER stress and unfolded 
protein response pathways in skeletal muscle health and disease. J Cell Physiol.

Cao L, Morley JE (2016). Sarcopenia Is Recognized as an Independent Condition by an International Classification of Disease, Tenth Revision, Clinical Modification (ICD-10-CM) Code. J Am Med Dir Assoc 17:675-677.

Chacon-Cabrera A, Lund-Palau H, Gea J, Barreiro E (2016). Time-Course of Muscle Mass Loss, Damage, and Proteolysis in Gastrocnemius following Unloading and Reloading: Implications in Chronic Diseases. PLoS One 11:e0164951.

Chakrabarti A, Chen AW, Varner JD (2011). A review of the mammalian unfolded protein response. Biotechnol Bioeng 108:2777-2793.

Chansky K, Detterbeck FC, Nicholson AG, Rusch VW, Vallieres E, Groome P, Kennedy C, Krasnik M, Peake M, Shemanski L, Bolejack V, Crowley JJ, Asamura H, Rami-Porta R (2017). The IASLC Lung Cancer Staging Project: External Validation of the Revision of the TNM Stage Groupings in the Eighth Edition of the TNM Classification of Lung Cancer. J Thorac Oncol 12:1109-1121.

Coin A, Sergi G, Minicuci N, Giannini S, Barbiero E, Manzato E, Pedrazzoni M, Minisola S, Rossini M, Del Puente A, Zamboni M, Inelmen EM, Enzi G (2008). Fat-free mass and fat mass reference values by dual-energy X-ray absorptiometry (DEXA) in a 20-80 year-old Italian population. Clin Nutr 27:87-94.

Coronell C, Orozco-Levi M, Mendez R, Ramirez-Sarmiento A, Galdiz JB, Gea J (2004). Relevance of assessing quadriceps endurance in patients with COPD. Eur Respir J 24:129136.

Evans WJ, Morley JE, Argiles J, Bales C, Baracos V, Guttridge D, Jatoi A, Kalantar-Zadeh K, Lochs H, Mantovani G, Marks D, Mitch WE, Muscaritoli M, Najand A, Ponikowski P, Rossi FF, Schambelan M, Schols A, Schuster M, Thomas D, Wolfe R, Anker SD (2008). Cachexia: a new definition. Clin Nutr 27:793-799.

Fearon K, Strasser F, Anker SD, Bosaeus I, Bruera E, Fainsinger RL, Jatoi A, Loprinzi C, MacDonald N, Mantovani G, Davis M, Muscaritoli M, Ottery F, Radbruch L, Ravasco P, Walsh D, Wilcock A, Kaasa S, Baracos VE (2011). Definition and classification of cancer cachexia: an international consensus. Lancet Oncol 12:489-495.

Fermoselle C, Rabinovich R, Ausin P, Puig-Vilanova E, Coronell C, Sanchez F, Roca J, Gea J, Barreiro E (2012). Does oxidative stress modulate limb muscle atrophy in severe COPD patients? Eur Respir J 40:851-862.

Gea J, Martinez-Llorens J (2018). Muscle Dysfunction in Chronic Obstructive Pulmonary Disease: Latest Developments. Arch Bronconeumol.

Gea J, Pascual S, Castro-Acosta A, Hernandez-Carcereny C, Castelo R, Marquez-Martin E, Monton C, Palou A, Faner R, Furlong LI, Seijo L, Sanz F, Tora M, Vilaplana C, Casadevall C, Lopez-Campos JL, Monso E, Peces-Barba G, Cosio BG, Agusti A (2018a). The BIOMEPOC Project: Personalized Biomarkers and Clinical Profiles in Chronic Obstructive Pulmonary Disease. Arch Bronconeumol.

Gea J, Sancho-Munoz A, Chalela R (2018b). Nutritional status and muscle dysfunction in 
chronic respiratory diseases: stable phase versus acute exacerbations. J Thorac Dis 10:S1332S1354.

Gosselink R, Troosters T, Decramer M (2000). Distribution of muscle weakness in patients with stable chronic obstructive pulmonary disease. J Cardiopulm Rehabil 20:353-360.

Guo Y, Gosker HR, Schols AM, Kapchinsky S, Bourbeau J, Sandri M, Jagoe RT, Debigare R, Maltais F, Taivassalo T, Hussain SN (2013). Autophagy in locomotor muscles of patients with chronic obstructive pulmonary disease. Am J Respir Crit Care Med 188:1313-1320.

Hassan T, Carroll TP, Buckley PG, Cummins R, O'Neill SJ, McElvaney NG, Greene CM (2014). miR-199a-5p silencing regulates the unfolded protein response in chronic obstructive pulmonary disease and alphal-antitrypsin deficiency. Am J Respir Crit Care Med 189:263273.

Hiramatsu N, Messah C, Han J, LaVail MM, Kaufman RJ, Lin JH (2014). Translational and posttranslational regulation of XIAP by eIF2alpha and ATF4 promotes ER stress-induced cell death during the unfolded protein response. Mol Biol Cell 25:1411-1420.

Hu P, Han Z, Couvillon AD, Kaufman RJ, Exton JH (2006). Autocrine tumor necrosis factor alpha links endoplasmic reticulum stress to the membrane death receptor pathway through IRE1 alpha-mediated NF-kappaB activation and down-regulation of TRAF2 expression. Mol Cell Biol 26:3071-3084.

Jaitovich A, Barreiro E (2018). Skeletal Muscle Dysfunction in Chronic Obstructive Pulmonary Disease. What We Know and Can Do for Our Patients. Am J Respir Crit Care Med 198:175-186.

Kelsen SG (2016). The Unfolded Protein Response in Chronic Obstructive Pulmonary Disease. Ann Am Thorac Soc 13 Suppl 2:S138-S145.

Lawson WE, Cheng DS, Degryse AL, Tanjore H, Polosukhin VV, Xu XC, Newcomb DC, Jones BR, Roldan J, Lane KB, Morrisey EE, Beers MF, Yull FE, Blackwell TS (2011). Endoplasmic reticulum stress enhances fibrotic remodeling in the lungs. Proc Natl Acad Sci U S A 108:10562-10567.

Livak KJ, Schmittgen TD (2001). Analysis of relative gene expression data using real-time quantitative PCR and the 2(-Delta Delta C(T)) Method. Methods 25:402-408.

Maltais F, Decramer M, Casaburi R, Barreiro E, Burelle Y, Debigare R, Dekhuijzen PN, Franssen F, Gayan-Ramirez G, Gea J, Gosker HR, Gosselink R, Hayot M, Hussain SN, Janssens W, Polkey MI, Roca J, Saey D, Schols AM, Spruit MA, Steiner M, Taivassalo T, Troosters T, Vogiatzis I, Wagner PD (2014). An official American Thoracic

Society/European Respiratory Society statement: update on limb muscle dysfunction in chronic obstructive pulmonary disease. Am J Respir Crit Care Med 189:e15-e62.

Marquis K, Debigare R, Lacasse Y, LeBlanc P, Jobin J, Carrier G, Maltais F (2002). Midthigh muscle cross-sectional area is a better predictor of mortality than body mass index in patients with chronic obstructive pulmonary disease. Am J Respir Crit Care Med 166:809-813.

Miravitlles M, Soler-Cataluna JJ (2017). GOLD in 2017: A View From the Spanish COPD Guidelines (GesCOPD). Arch Bronconeumol 53:89-90. 
Miravitlles M, Soler-Cataluna JJ, Calle M, Molina J, Almagro P, Quintano JA, Trigueros JA, Cosio BG, Casanova C, Antonio RJ, Simonet P, Rigau D, Soriano JB, Ancochea J (2017). Spanish Guidelines for Management of Chronic Obstructive Pulmonary Disease (GesEPOC) 2017. Pharmacological Treatment of Stable Phase. Arch Bronconeumol 53:324-335.

Muscaritoli M, Anker SD, Argiles J, Aversa Z, Bauer JM, Biolo G, Boirie Y, Bosaeus I, Cederholm T, Costelli P, Fearon KC, Laviano A, Maggio M, Rossi FF, Schneider SM, Schols A, Sieber CC (2010). Consensus definition of sarcopenia, cachexia and pre-cachexia: joint document elaborated by Special Interest Groups (SIG) "cachexia-anorexia in chronic wasting diseases" and "nutrition in geriatrics". Clin Nutr 29:154-159.

Nakanishi K, Sudo T, Morishima N (2005). Endoplasmic reticulum stress signaling transmitted by ATF6 mediates apoptosis during muscle development. J Cell Biol 169:555560 .

Nguyen DT, Kebache S, Fazel A, Wong HN, Jenna S, Emadali A, Lee EH, Bergeron JJ, Kaufman RJ, Larose L, Chevet E (2004). Nck-dependent activation of extracellular signalregulated kinase-1 and regulation of cell survival during endoplasmic reticulum stress. Mol Biol Cell 15:4248-4260.

Puig-Vilanova E, Aguilo R, Rodriguez-Fuster A, Martinez-Llorens J, Gea J, Barreiro E (2014a). Epigenetic mechanisms in respiratory muscle dysfunction of patients with chronic obstructive pulmonary disease. PLoS One 9:e111514.

Puig-Vilanova E, Ausin P, Martinez-Llorens J, Gea J, Barreiro E (2014b). Do epigenetic events take place in the vastus lateralis of patients with mild chronic obstructive pulmonary disease? PLoS One 9:e102296.

Puig-Vilanova E, Martinez-Llorens J, Ausin P, Roca J, Gea J, Barreiro E (2015). Quadriceps muscle weakness and atrophy are associated with a differential epigenetic profile in advanced COPD. Clin Sci (Lond) 128:905-921.

Puig-Vilanova E, Rodriguez DA, Lloreta J, Ausin P, Pascual-Guardia S, Broquetas J, Roca J, Gea J, Barreiro E (2014c). Oxidative stress, redox signaling pathways, and autophagy in cachectic muscles of male patients with advanced COPD and lung cancer. Free Radic Biol Med 79C:91-108.

Rowlands AG, Panniers R, Henshaw EC (1988). The catalytic mechanism of guanine nucleotide exchange factor action and competitive inhibition by phosphorylated eukaryotic initiation factor 2. J Biol Chem 263:5526-5533.

Salazar-Degracia A, Blanco D, Vila-Ubach M, de BG, de Solorzano CO, Montuenga LM, Barreiro E (2016). Phenotypic and metabolic features of mouse diaphragm and gastrocnemius muscles in chronic lung carcinogenesis: influence of underlying emphysema. J Transl Med $14: 244$.

Salazar-Degracia A, Busquets S, Argiles JM, Bargallo-Gispert N, Lopez-Soriano FJ, Barreiro E (2018). Effects of the beta2 agonist formoterol on atrophy signaling, autophagy, and muscle phenotype in respiratory and limb muscles of rats with cancer-induced cachexia. Biochimie 149:79-91.

Schroder M, Kaufman RJ (2005). The mammalian unfolded protein response. Annu Rev 
Biochem 74:739-789.

Seymour JM, Spruit MA, Hopkinson NS, Natanek SA, Man WD, Jackson A, Gosker HR, Schols AM, Moxham J, Polkey MI, Wouters EF (2010). The prevalence of quadriceps weakness in COPD and the relationship with disease severity. Eur Respir J 36:81-88.

Shrikrishna D, Patel M, Tanner RJ, Seymour JM, Connolly BA, Puthucheary ZA, Walsh SL, Bloch SA, Sidhu PS, Hart N, Kemp PR, Moxham J, Polkey MI, Hopkinson NS (2012). Quadriceps wasting and physical inactivity in patients with COPD. Eur Respir J 40:11151122 .

Steiner MC, Barton RL, Singh SJ, Morgan MD (2002). Bedside methods versus dual energy X-ray absorptiometry for body composition measurement in COPD. Eur Respir J 19:626-631.

Swallow EB, Reyes D, Hopkinson NS, Man WD, Porcher R, Cetti EJ, Moore AJ, Moxham J, Polkey MI (2007). Quadriceps strength predicts mortality in patients with moderate to severe chronic obstructive pulmonary disease. Thorax 62:115-120.

Vogelmeier CF, Criner GJ, Martinez FJ, Anzueto A, Barnes PJ, Bourbeau J, Celli BR, Chen R, Decramer M, Fabbri LM, Frith P, Halpin DM, Lopez Varela MV, Nishimura M, Roche N, Rodriguez-Roisin R, Sin DD, Singh D, Stockley R, Vestbo J, Wedzicha JA, Agusti A (2017). Global Strategy for the Diagnosis, Management, and Prevention of Chronic Obstructive Lung Disease 2017 Report: GOLD Executive Summary. Arch Bronconeumol 53:128-149.

Xiong G, Hindi SM, Mann AK, Gallot YS, Bohnert KR, Cavener DR, Whittemore SR, Kumar A (2017). The PERK arm of the unfolded protein response regulates satellite cellmediated skeletal muscle regeneration. Elife 6. 


\section{FIGURE LEGENDS}

Figure 1: (A) Mean values and 95\% confidence intervals of expression levels of the following markers: BIP, HSP60, HSP70, CALNEXIN, CALRETICULIN, PDIA3 and PI3K expressed as relative mRNA levels in the vastus lateralis muscle of the study groups: healthy controls, LC-cachexia and COPD patients. (B) Mean values and 95\% confidence intervals of BIP protein content in the vastus lateralis muscle as measured by optical densities in arbitrary units (OD, a.u.). (C) Mean values and 95\% confidence intervals of PDIA3 protein content in the vastus lateralis muscle as measured by optical densities in arbitrary units (OD, a.u.). (D) Mean values and $95 \%$ confidence intervals of PI3K protein content in the vastus lateralis muscle as measured by optical densities in arbitrary units (OD, a.u.). Definition of abbreviations: BIP, binding immunoglobulin protein; HSP, heat shock protein; PDIA3, protein disulfide isomerase family A member 3; PI3K, phosphatidylinositol 3-kinase. Statistical significance: $* \mathrm{p} \leq 0.05, * * \mathrm{p} \leq 0.01$ and $* * * \mathrm{p} \leq 0.001$ between either the LCcachexia patients or any of COPD patient groups (non-sarcopenic and sarcopenic patients) and the healthy controls; $\S \S \S \mathrm{p} \leq 0.001$ between the non-sarcopenic and the sarcopenic COPD patients.

Figure 2: (A) Mean values and 95\% confidence intervals of expression levels of ATF6 marker expressed as relative mRNA levels in the vastus lateralis muscle of the study groups: healthy controls, LC-cachexia and COPD patients. (B) Mean values and 95\% confidence intervals of ATF6 protein content in the vastus lateralis muscle as measured by optical densities in arbitrary units (OD, a.u.). Definition of abbreviations: ATF, activating transcription factor; Statistical significance: $* \mathrm{p} \leq 0.05$ and $* * \mathrm{p} \leq 0.01$ between either the LCcachexia patients or any of COPD patient groups (non-sarcopenic and sarcopenic patients) and the healthy controls. 
Figure 3: (A) Mean values and 95\% confidence intervals of expression levels of the following markers: PERK, ATF4 and CHOP expressed as relative mRNA levels in the vastus lateralis muscle of the study groups: healthy controls, LC-cachexia and COPD patients. (B) Mean values and 95\% confidence intervals of activated PERK protein content in the vastus lateralis muscle as measured by optical densities in arbitrary units ( $O D$, a.u.). (C) Mean values and $95 \%$ confidence intervals of activated $\mathrm{EiF} 2 \alpha$ protein content in the vastus lateralis muscle as measured by optical densities in arbitrary units (OD, a.u.). (D) Mean values and $95 \%$ confidence intervals of $\mathrm{CHOP}$ protein content in the vastus lateralis muscle as measured by optical densities in arbitrary units (OD, a.u.). Definition of abbreviations: PERK, protein kinase $\mathrm{R}$ (PKR)-like endoplasmic reticulum kinase; ATF, activating transcription factor; CHOP, C/EBP-homologous protein; $\mathrm{EiF} 2 \alpha$, eukaryotic translation initation factor 2 alpha. Statistical significance: $* \mathrm{p} \leq 0.05$ and $* * * \mathrm{p} \leq 0.001$ between either the LC-cachexia patients or any of COPD patient groups (non-sarcopenic and sarcopenic patients) and the healthy controls.

Figure 4: (A) Mean values and 95\% confidence intervals of expression levels of the following markers: IRE1, TRAF2 and XBP1 expressed as relative mRNA levels in the vastus lateralis muscle of the study groups: healthy controls, LC-cachexia and COPD patients. (B) Mean values and $95 \%$ confidence intervals of IRE1 protein content in the vastus lateralis muscle as measured by optical densities in arbitrary units (OD, a.u.). (C) Mean values and $95 \%$ confidence intervals of TRAF2 protein content in the vastus lateralis muscle as measured by optical densities in arbitrary units (OD, a.u.). (D) Mean values and $95 \%$ confidence intervals of unspliced XBP1u protein content in the vastus lateralis muscle as measured by optical densities in arbitrary units (OD, a.u.). (E) Mean values and 95\% confidence intervals of spliced XBP1s protein content in the vastus lateralis muscle as measured by optical densities in arbitrary units (OD, a.u.). Definition of abbreviations: IRE1, endoplasmic 
reticulum to nucleus signaling 1; TRAF2, TNF receptor associated factor 2; XBP1, X-box binding protein 1. Statistical significance: $* \mathrm{p} \leq 0.05$, $* * \mathrm{p} \leq 0.01$ and $* * * \mathrm{p} \leq 0.001$ between either the LC-cachexia patients or any of COPD patient groups (non-sarcopenic and sarcopenic patients) and the healthy controls.

Figure 5: (A) Mean values and 95\% confidence intervals of expression levels of the following markers: Atrogin-1 and MuRF-1 expressed as relative mRNA levels in the vastus lateralis muscle of the study groups: healthy controls, LC-cachexia and COPD patients. (B) Mean values and $95 \%$ confidence intervals of LC3B protein content in the vastus lateralis muscle as measured by optical densities in arbitrary units (OD, a.u.). (C) Mean values and $95 \%$ confidence intervals of $\mathrm{p} 62$ protein content in the vastus lateralis muscle as measured by optical densities in arbitrary units (OD, a.u.). (D) Mean values and 95\% confidence intervals of MDA-protein adducts in the vastus lateralis muscle as measured by optical densities in arbitrary units (OD, a.u.). Definition of abbreviations: MuRF-1, muscle ring finger protein-1; LC3B, microtube-associated protein 1 light chain 3; p62, nucleoporin p62; MDA, malondialdehyde. Statistical significance: * $\mathrm{p} \leq 0.05, * * \mathrm{p} \leq 0.01$ and $* * * \mathrm{p} \leq 0.001$ between either the LC-cachexia patients or any of COPD patient groups (non-sarcopenic and sarcopenic patients) and the healthy controls; $\S \S \mathrm{p} \leq 0.01$ between the non-sarcopenic and the sarcopenic COPD patients.

Figure 6: (A) Mean values and $95 \%$ confidence intervals of expression levels of the following markers: CASPASE3, CASPASE7, CASPASE9, ASK, BAX and BCL2L11 expressed as relative mRNA levels in the vastus lateralis muscle of the study groups: healthy controls, LC-cachexia and COPD patients. (B) Mean values and 95\% confidence intervals of ASK1 protein content in the vastus lateralis muscle as measured by optical densities in arbitrary units (OD, a.u.). Definition of abbreviations: ASK1, apoptosis signal-regulating kinase 1; BAX, BCL2 associated X apoptotic regulator; BCL2L11, BCL2 like 11 apoptosis regulator 
Bcl-2;. Statistical significance: $* \mathrm{p} \leq 0.05, * * \mathrm{p} \leq 0.01$ and $* * * \mathrm{p} \leq 0.001$ between either the LC-cachexia patients or any of COPD patient groups (non-sarcopenic and sarcopenic patients) and the healthy controls. 
Table 1. Anthropometric characteristics and functional status of the study subjects

11 Anthropometry

${ }_{13}^{12}$ Age (years)

14 BMI $\left(\mathrm{kg} / \mathrm{m}^{2}\right)$

15 FFMI $\left(\mathrm{kg} / \mathrm{m}^{2}\right)$

${ }_{17}^{16}$ Body weight (kg)

18 Body weight change $(\mathrm{kg} / \mathrm{last}$

19 year)

21 Lung cancer staging, \%

22

23

24 Smoking history

25 Active (N,\%)

${ }_{27}^{26}$ Ex-smoker (N,\%)

28 Never smoker (N,\%)

29 Packs-year

${ }_{31}^{30}$ Lung function

$32 \mathrm{FEV}_{1}$ (\% pred)

$33 \mathrm{FVC}$ (\% pred)

${ }_{35}^{34} \mathrm{FEV}_{1} / \mathrm{FVC}(\%)$

${ }_{36} \mathrm{RV}$ (\% pred)

37 TLC (\% pred)

${ }_{39}^{38} \mathrm{RV} / \mathrm{TLC}$

40 DLco (\% pred)

$41 \mathrm{Kco}$ (\% pred)

${ }^{42} \mathrm{PaO}_{2}(\mathrm{kPa})$

${ }_{44} \mathrm{PaCO}_{2}(\mathrm{kPa})$

45 Exercise capacity and muscle function

$46 \mathrm{V0}_{2}$ peak (\% pred)

48 WR peak (\% pred)

496 -min walking test $(\mathrm{m})$

${ }_{51}^{50}$ QMVC (kg)

52 Blood parameters

53 Albumin (g/dl)

54 Total proteins $(\mathrm{g} / \mathrm{dl})$

${ }_{56}^{55}$ CRP (mg/dl)

57 Fibrinogen $(\mathrm{mg} / \mathrm{dl})$

$58 \mathrm{GSV}(\mathrm{mm} / \mathrm{h})$

59

60

$19(3)$

$0(0)$

All COPD patients

\begin{tabular}{lll:ll} 
Healthy & LC-cachexia & All COPD & Non-sarcopenic & Sarcopenic \\
controls & patients & patients & COPD & COPD \\
$\mathrm{N}=19$ & $\mathrm{~N}=13$ & $\mathrm{~N}=40$ & $\mathrm{~N}=19$ & $\mathrm{~N}=21$ \\
\hline
\end{tabular}

\begin{tabular}{lll|l}
$66(7)$ & $68(9)$ & $68(5)$ & $68(5)$
\end{tabular}

$27(2)$

18 (1)

$23(2)^{*}$

$24(5)^{* *}$

67 (5)

$21(3)^{* * *}, \S \S \S$

$16(2)^{* * *}, \S$

$62(10)^{* * *,} \S \S \S$

$-2.4(1.8)^{* * *, \S}$

$66(7)^{*}$

$17(2)^{* *}$

74 (4)

$-0.2(2.3)$

NA

$\begin{array}{ll}\text { NA } & \text { I/III/IV } \\ & 30 / 30 / 40\end{array}$

NA

NA

6,32

9,47

$9,69 * *$

$24,60 * *$

$10,53 *$

$16,40 * *$

$9,47 *$

$0,0 * *$

0,0 *

$61(28)$

$54(22) \quad 58(12)$

62 (24)

90 (12)

$61(22)^{* *}$

90 (12)

$72(18)^{* *}$

74 (4)

$65(18)^{* *}$

104 (20)

96 (46)

97 (13)

85 (20)

$43(5)$

51 (13)

88 (19)

75 (18)

86 (17)

94 (23)

$11.3(1.3)$

$10.5(1.0)$

$5.3(0.5)$

$5.2(0.5)$

83 (15)

$57(10)^{* *}$

$40(19)^{* * *}$

$64(18)^{* * *}$

$44(19)^{* * * *}$

$65(19)^{* * *}$

$48(12)^{* * *}$

$178(78)^{* * *}$

$101(26)$

$58(13)^{* * *}$

$56(24)^{* * *}$

$60(20)^{* * *}$

$9.7(1.4)^{* *}$

$5.3(0.7)$

$57(20)^{* * *}$

$49(21)^{*}$

425 (112)

$31(3) * * *$

$4.3(0.3)$

$7.2(0.6)$

$0.6(0.5)$

$444(85)$

$18(11)$
$14,67^{*}$

$7,33 *$

$0,0^{*}$

62 (19)

$35(19)^{* * *, \mathrm{p}=0.096}$

$62(17)^{* * *}$

$46(13)^{* * *}$

$182(71)^{* * *}$

107 (18)

$64(12)^{* * *}$

$53(30)^{* * *}$

$70(24) *$

$9.9(1.7)^{*}$

$5.6(0.8)$

$48(22)^{* * *}$

$38(17)^{* * *}$

425 (132)

$29(3) * * *$

$4.3(0.6)$

$7.2(0.6)$

$1.6(2.4)^{*}$

464 (99)

$21(20)^{*}$ 
Values are expressed as mean (standard deviation).

Abbreviations: LC, lung cancer; COPD, chronic obstructive pulmonary disease; N, number of patients; m, meters; kg, kilograms; BMI, body mass index; FFMI, fat-free mass index; NA, not applicable; FEV1, forced expiratory volume in one second; pred, predicted; FVC, forced vital capacity; RV, residual volume; TLC, total lung capacity; DLco, carbon monoxide transfer; $\mathrm{KCO}$, Krough transfer factor; $\mathrm{PaO}_{2}$, arterial oxygen partial pressure; $\mathrm{kPa}$, kilopascals; $\mathrm{PaCO}_{2}$, arterial carbon dioxide partial pressure; $\mathrm{VO}_{2}$ peak, peak exercise oxygen uptake; WR peak, peak work rate; QMVC, quadriceps maximal velocity contraction; g, grams; dL, deciliter; CRP, C-reactive protein; mg, milligrams; GSV, globular sedimentation velocity; mm, millimeters; $\mathrm{h}$, hour. Statistical significance: * $\mathrm{p} \leq 0.05, * * \mathrm{p} \leq 0.01$ and $* * * \mathrm{p} \leq 0.001$ between either LCcachexia patients or any group of COPD patients (as a whole and separately, non-sarcopenic and sarcopenic COPD patients) and the healthy control subjects; $\S p \leq 0.05$ and $\S \S \S p \leq 0.001$ between the non-sarcopenic and the sarcopenic COPD patients. 
Table 2. Main clinical characteristics and functional variables of the study subjects

\begin{tabular}{|c|c|c|c|}
\hline & \multirow{2}{*}{ Controls } & \multicolumn{2}{|c|}{ Severe COPD } \\
\hline & & Non-cachectic & Cachectic \\
\hline Subjects & $\mathrm{N}=10$ & $\mathrm{~N}=14$ & $\mathrm{~N}=15$ \\
\hline Female/male & $4 / 6$ & $3 / 11$ & $2 / 13$ \\
\hline \multicolumn{4}{|l|}{ Anthropometry } \\
\hline Age (years) & $62(6)$ & $67(10)$ & $65(9)$ \\
\hline BMI $\left(\mathrm{kg} / \mathrm{m}^{2}\right)$ & $27(2)$ & $26(3)$ & $18(2) * * *, \S \S \S$ \\
\hline FFMI $\left(\mathrm{kg} / \mathrm{m}^{2}\right)$ & $19(2)$ & $18(2)$ & $15(1) * * *, \S \S \S$ \\
\hline \multicolumn{4}{|l|}{ Smoking History } \\
\hline Active, N, \% & 0,0 & $6,43 * * *$ & $6,40 * * *$ \\
\hline Ex-smoker, N, \% & 5,50 & $8,57 * * *$ & $9,60 * * *$ \\
\hline Never smoker, N, \% & 5,50 & $0,0 * * *$ & $0,0 * * *$ \\
\hline Pack-years & $62(16)$ & $69(18)$ & $66(31)$ \\
\hline \multicolumn{4}{|l|}{ Lung function } \\
\hline $\mathrm{FEV}_{1}(\%$ pred $)$ & & $35(11) * * *$ & $31(12) * * *$ \\
\hline FVC (\% pred) & $92(8)$ & $54(16) * * *$ & $58(18) * * *$ \\
\hline $\mathrm{FEV}_{1} / \mathrm{FVC}(\%)$ & $75(3)$ & $45(10) * * *$ & $40(11) * * *$ \\
\hline RV (\% pred) & $115(18)$ & $195(53) * *$ & $210(69) * * *$ \\
\hline TLC (\% pred) & $104(10)$ & $115(20)$ & $119(17)$ \\
\hline RV/TLC (\%) & $43(3)$ & $66(9) * * *$ & $69(11) * * *$ \\
\hline DLco (\% pred) & $102(16)$ & $49(21) * * *$ & $42(18) * * *$ \\
\hline $\mathrm{K}_{\mathrm{CO}}(\%$ pred $)$ & $94(14)$ & $58(21) * * *$ & $57(21) * * *$ \\
\hline $\mathrm{PaO}_{2}(\mathrm{mmHg})$ & $85(2.7)$ & $68(9.5) * * *$ & $65(8.8) * * *$ \\
\hline $\mathrm{PaCO}_{2}(\mathrm{mmHg})$ & $42(4.2)$ & $46(4.5)$ & $45(5.3)$ \\
\hline \multicolumn{4}{|l|}{ Exercise capacity \& muscle force } \\
\hline QMVC (kg) & $44(11)$ & $32(8) *$ & $23(11) * * *, \S$ \\
\hline Six-minute walking distance $(\mathrm{m})$ & $526(47)$ & $408(111) *$ & $380(113) * *$ \\
\hline \multicolumn{4}{|l|}{ Blood parameters } \\
\hline Albumin $(\mathrm{g} / \mathrm{dL})$ & $4.5(0.4)$ & $4.2(0.4)$ & $4.6(0.9)$ \\
\hline Total proteins (g/dL) & $6.3(1.5)$ & $6.9(0.7)$ & $6.7(1.2)$ \\
\hline $\mathrm{CRP}(\mathrm{mg} / \mathrm{dL})$ & $0.9(0.6)$ & $1.7(0.5) *$ & $6.0(5.6) * *, \S \S$ \\
\hline Fibrinogen $(\mathrm{mg} / \mathrm{dL})$ & $384(108)$ & $416(90) *$ & $535(127) * \S$ \\
\hline $\mathrm{GSV}(\mathrm{mm} / \mathrm{h})$ & $15(7)$ & $29(13) *$ & $28(13) *$ \\
\hline
\end{tabular}

Values are expressed as mean (standard deviation).

Abbreviations: COPD, chronic obstructive pulmonary disease; $\mathrm{N}$, number of patients; kg, kilograms; m, meters; $\mathrm{BMI}$, body mass index; FFMI, fat-free mass index; $\mathrm{FEV}_{1}$, forced expiratory volume in one second; pred, predicted; FVC, forced vital capacity; RV, residual volume; TLC, total lung capacity; DLco, carbon monoxide transfer; $\mathrm{K}_{\mathrm{CO}}$, Krogh transfer factor for diffusing capacity; $\mathrm{PaO}_{2}$, arterial oxygen partial pressure; $\mathrm{mmHg}$, millimeter of mercuri; $\mathrm{PaCO}_{2}$, arterial carbon dioxide partial pressure; QMVC, quadriceps maximal velocity contraction; g, grams; dL, deciliter; CRP, C-reactive protein; mg, milligrams; GSV, globular sedimentation velocity; mm, millimeters; h, hour. 
Statistical significance: $*, \mathrm{p} \leq 0.05,{ }^{* *}, \mathrm{p} \leq 0.01,{ }^{* *}, \mathrm{p} \leq 0.001$ between any group of COPD patients and the control subjects; ${ }^{\S}, \mathrm{p} \leq 0.05, \S \S, \mathrm{p} \leq 0.01, \S \S \S, \mathrm{p} \leq 0.001$ between non-cachectic and cachectic patients. 
Barreiro et al. Figure 1

A

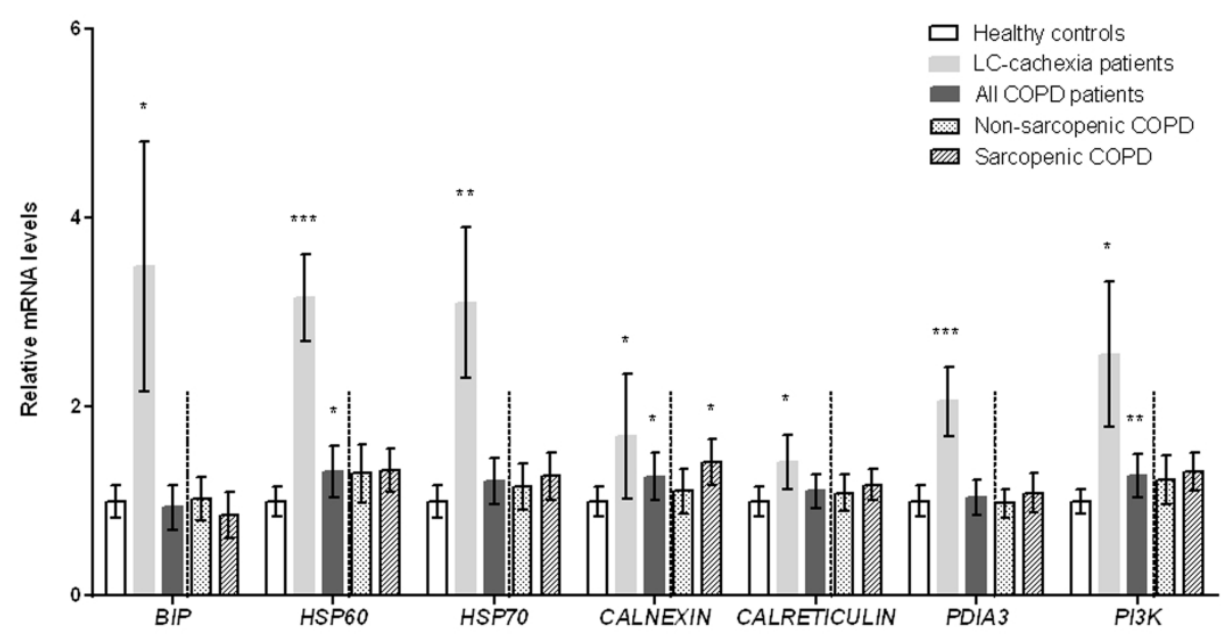

Figure $1 \mathrm{~A}$

$254 \times 190 \mathrm{~mm}(300 \times 300$ DPI)

John Wiley \& Sons, Inc. 


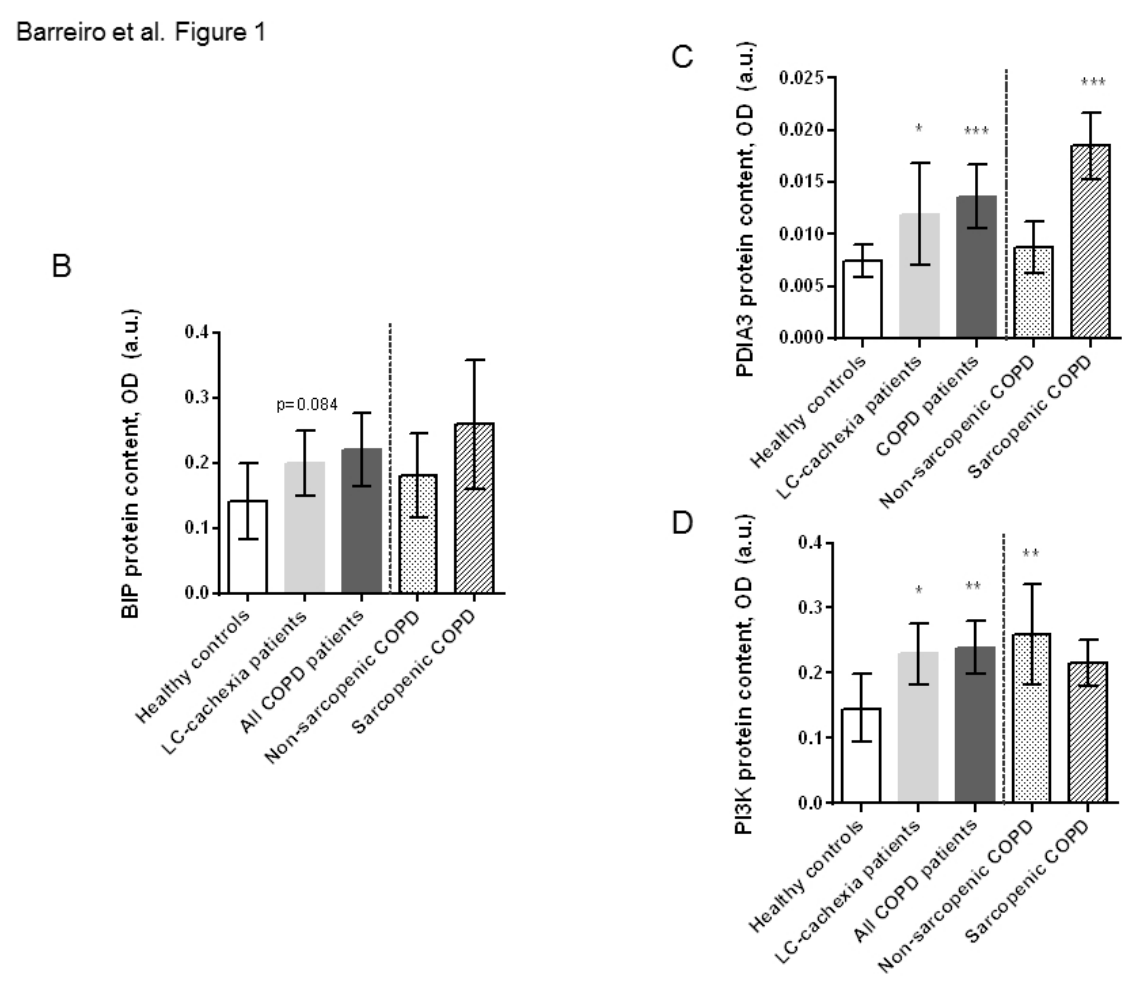

Figure 1B-1D

$254 \times 190 \mathrm{~mm}(96 \times 96 \mathrm{DPI})$

John Wiley \& Sons, Inc. 
Barreiro et al. Figure 2

A

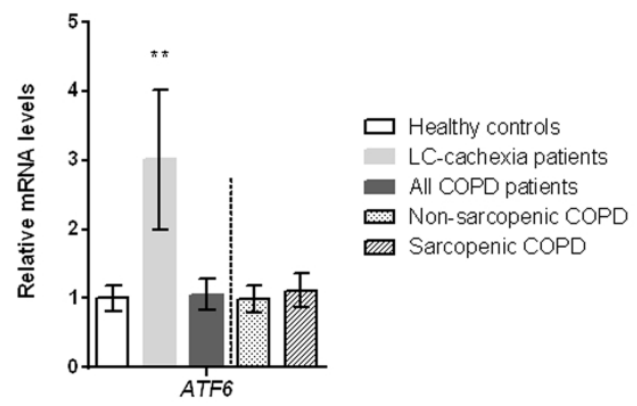

B

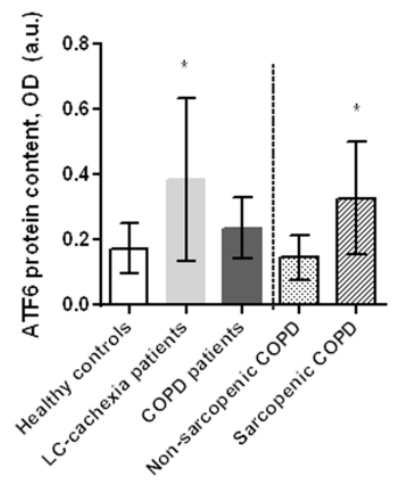

Figure 2

$254 \times 190 \mathrm{~mm}(300 \times 300$ DPI)

John Wiley \& Sons, Inc. 
Barreiro et al. Figure 3

A

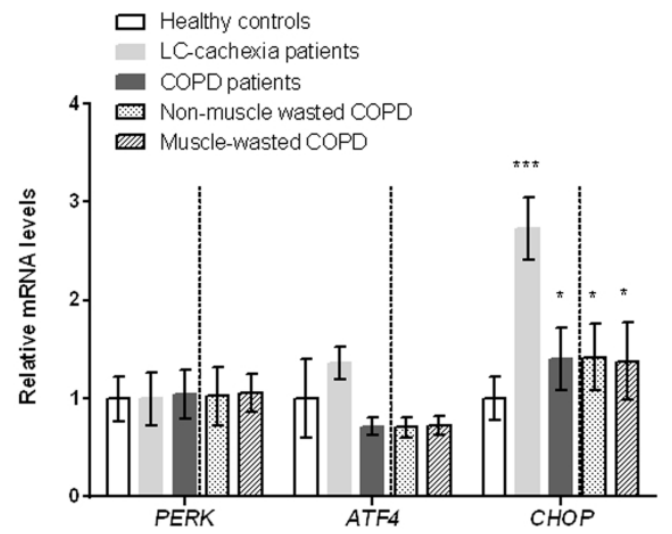

B

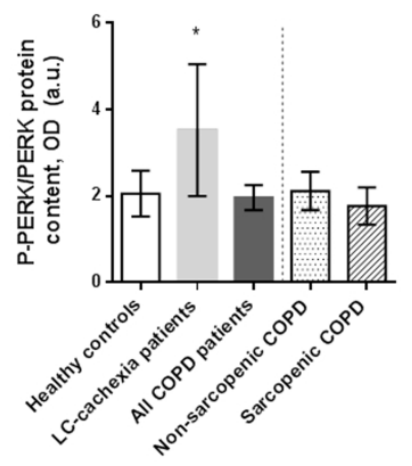

C

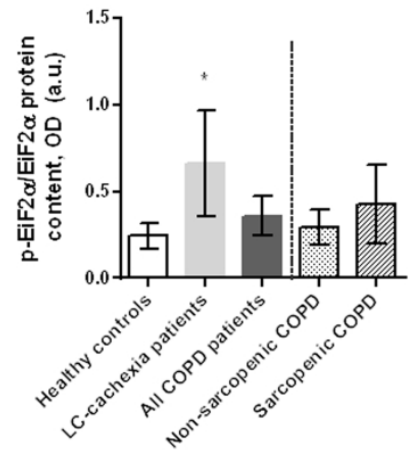

Figure $3 A-3 C$

$254 \times 190 \mathrm{~mm}(300 \times 300 \mathrm{DPI})$

John Wiley \& Sons, Inc. 

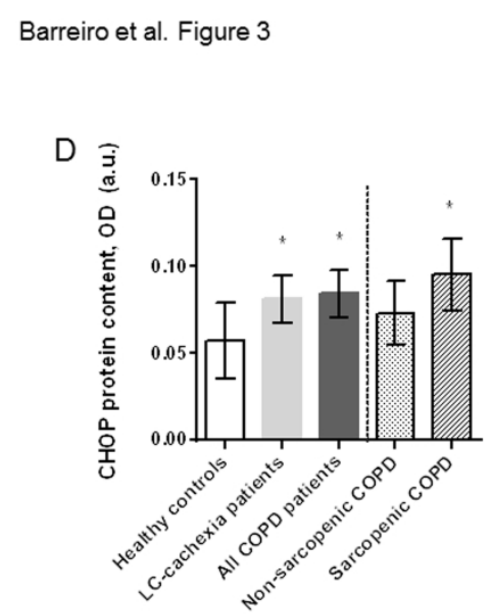

57

58

59

Figure 3D

$254 \times 190 m m(300 \times 300$ DPI $)$

John Wiley \& Sons, Inc. 


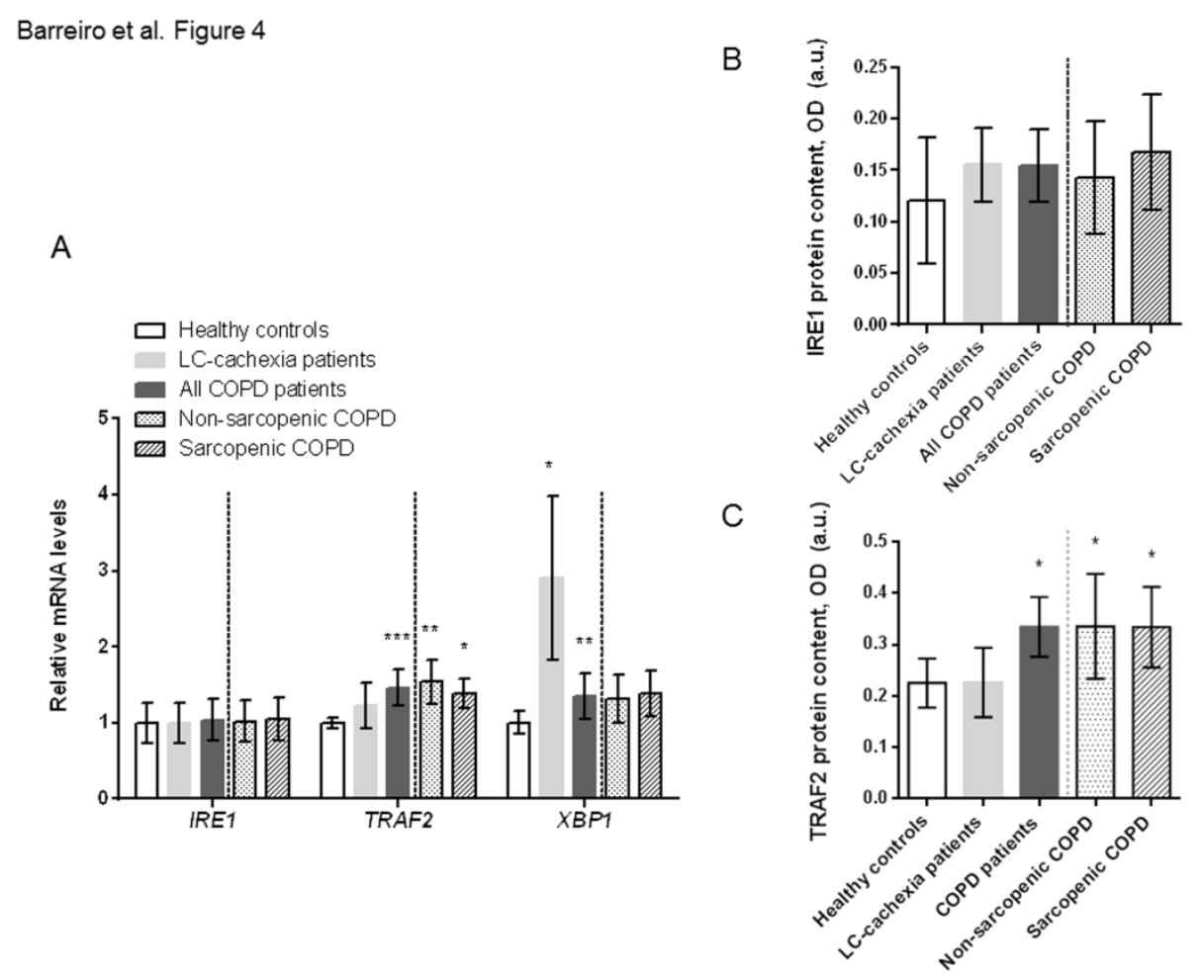

Figure $4 A-4 C$

$254 \times 190 \mathrm{~mm}(300 \times 300$ DPI)

John Wiley \& Sons, Inc. 
Barreiro et al. Figure 4

D

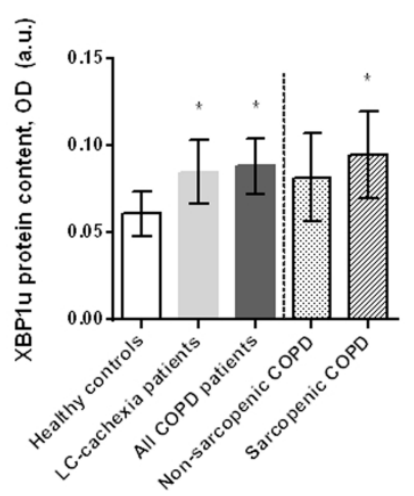

E

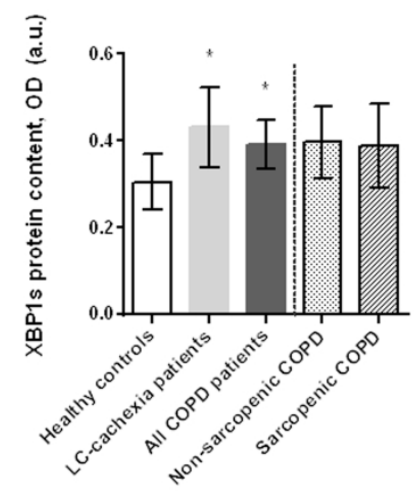

Figure 4D-4E

$254 \times 190 \mathrm{~mm}(300 \times 300 \mathrm{DPI})$

John Wiley \& Sons, Inc. 

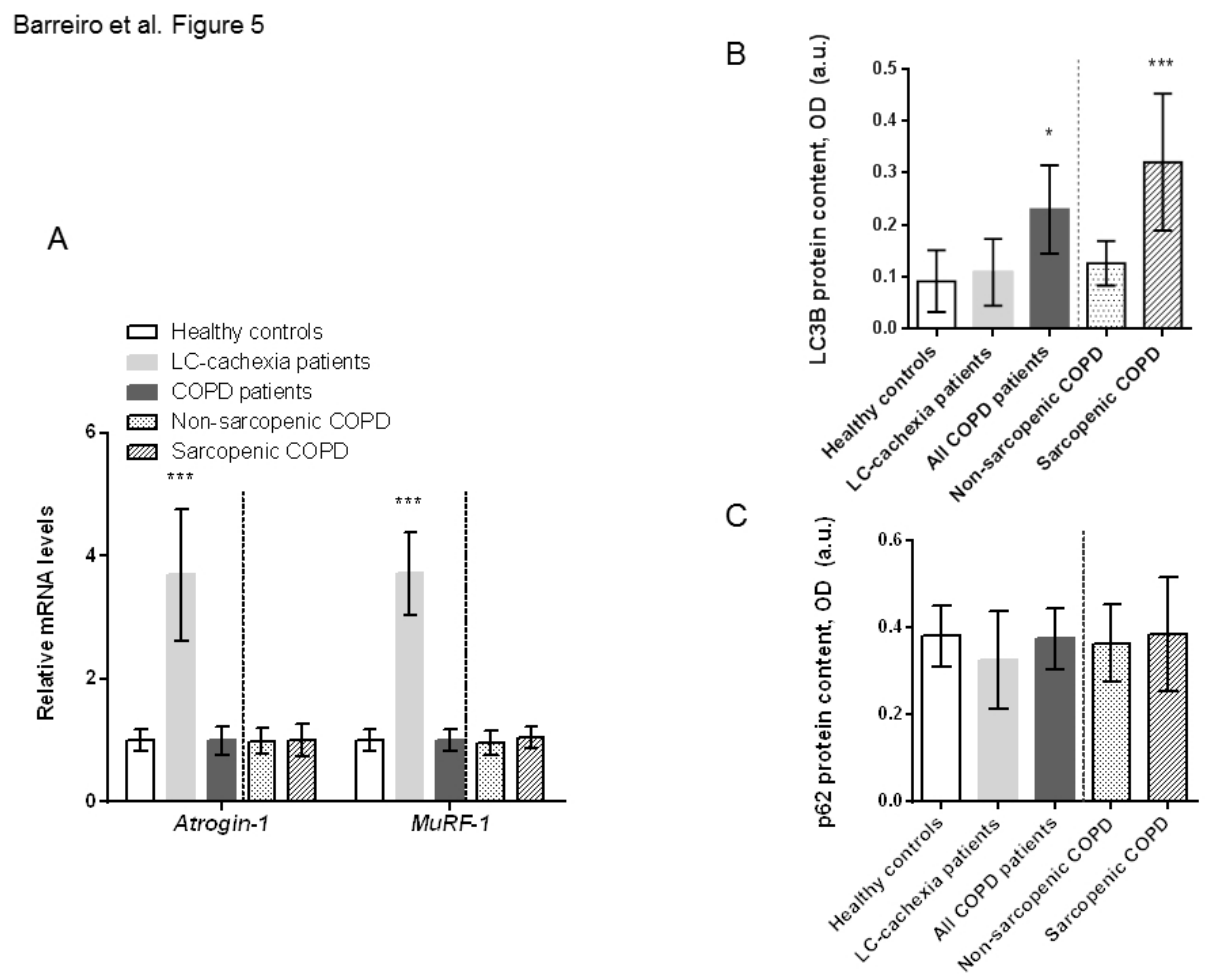

Figure $5 A-5 C$

254x190mm (96 x 96 DPI)

John Wiley \& Sons, Inc. 


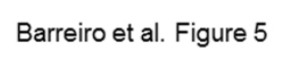

D

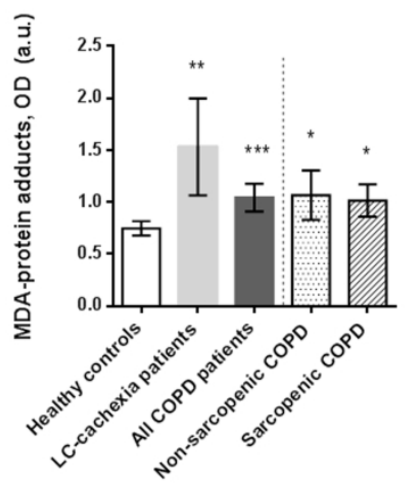

Figure 5D

$254 \times 190 \mathrm{~mm}(300 \times 300$ DPI $)$

John Wiley \& Sons, Inc. 
Barreiro et al. Figure 6

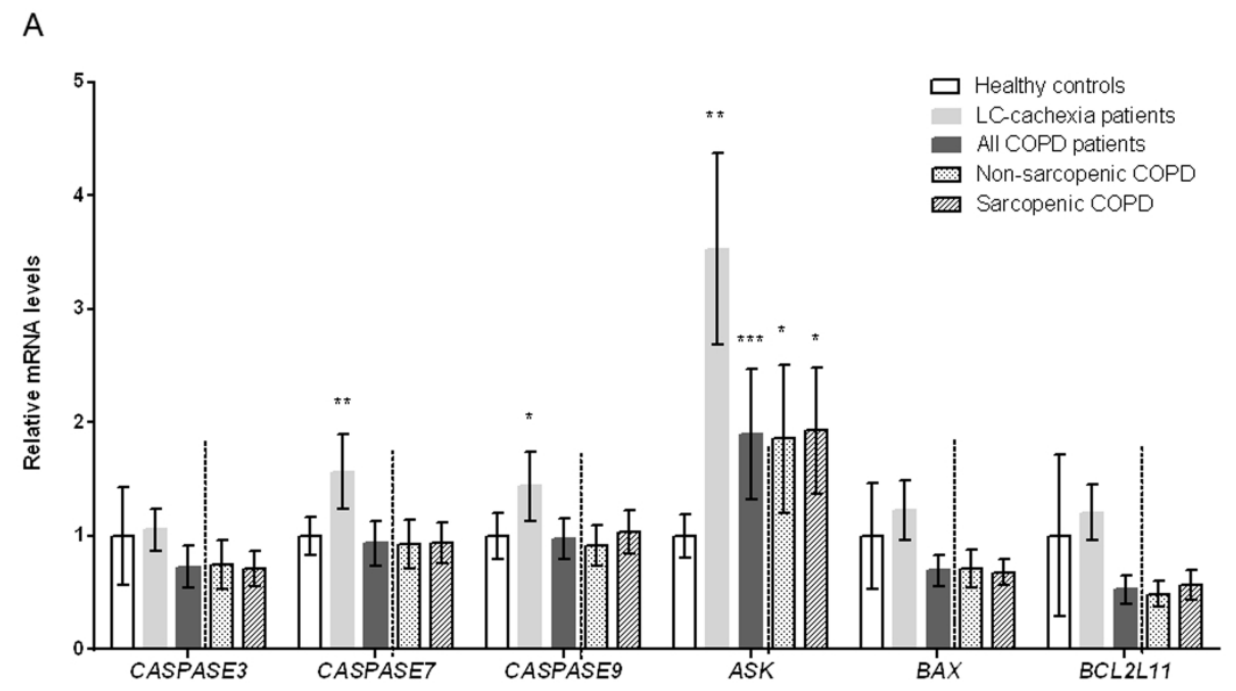

Figure 6A

$254 \times 190 \mathrm{~mm}(300 \times 300$ DPI)

John Wiley \& Sons, Inc. 


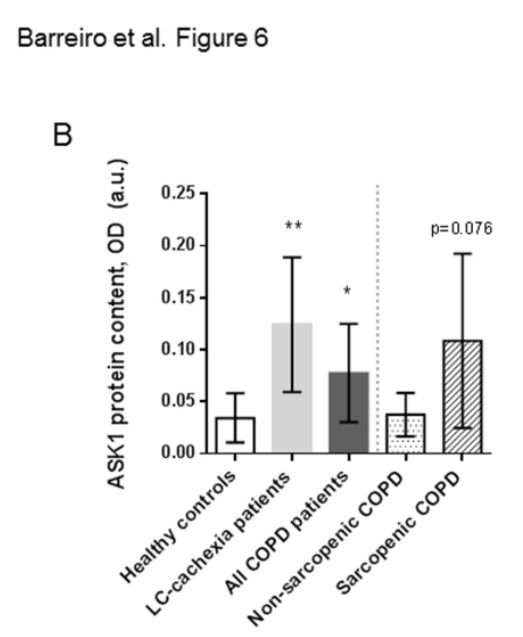

Figure 6B

$254 \times 190 \mathrm{~mm}(300 \times 300 \mathrm{DPI})$

John Wiley \& Sons, Inc. 